\title{
Bio-based polyurethane prepared from Kraft lignin and modified castor oil
}

\author{
L. B. Tavares, C. V. Boas, G. R. Schleder, A. M. Nacas, D. S. Rosa, D. J. Santos* \\ Centro de Engenharia, Modelagem e Ciências Sociais Aplicadas, UFABC, Santo André, 09210-580 São Paulo, Brazil
}

Received 24 April 2016; accepted in revised form 26 June 2016

\begin{abstract}
Current challenges highlight the need for polymer research using renewable natural sources as a substitute for petroleum-based polymers. The use of polyols obtained from renewable sources combined with the reuse of industrial residues such as lignin is an important agent in this process. Different compositions of polyurethane-type materials were prepared by combining technical Kraft lignin (TKL) with castor oil (CO) or modified castor oil (MCO1 and MCO2) to increase their reactivity towards diphenylmethane diisocyanate (MDI). The results indicate that lignin increases the glass transition temperature, the crosslinking density and improves the ultimate stress especially for those prepared from $\mathrm{MCO} 2$ and $30 \%$ lignin content from 8.2 MPa (lignin free) to 23.5 MPa. Scanning electron microscopy (SEM) micrographs of rupture surface after uniaxial tensile tests show ductile-to-brittle transition. The results show the possibility to develop polyurethane-type materials, varying technical grade Kraft lignin content, which cover a wide range of mechanical properties (from large elastic/low Young modulus to brittle/high Young modulus polyurethanes).
\end{abstract}

Keywords: mechanical properties, reinforcements, Kraft lignin, lignopolyurethane materials, modified castor oil

\section{Introduction}

Increasing concerns about depletion of petroleumbased resources and environmental problems caused by petroleum-based materials have led to considerable efforts to develop materials based on renewable resources such as vegetable oils, cellulose, lignin, starch, etc. [1]. The use of renewable raw materials can significantly contribute to sustainable development due to degradability and low toxicity of the resulting products. Conventional polyurethanes (PU) are usually synthesized by a polyaddition reaction between polyols, which are petrochemical in origin and polyisocyanate, which forms urethane linkages [2] resulting in a crosslinked polymer. Nevertheless, polyurethanes can be obtained by using renewable sources such as vegetable oils and can replace fossil fuel-derived oligomers partially or totally.

\footnotetext{
*Corresponding author, e-mail: demetrio.santos@ufabc.edu.br (C) BME-PT
}

Castor oil is a major candidate in these replacement efforts due to its inherent advantages over other vegetable oils [3]. Besides its renewability, low cost and easy availability in large quantities, castor oil is not edible, and does not compete with food, and has free secondary hydroxyl groups. Approximately $90 \%$ of fatty acids in castor oil are ricinoleic acid (C18:1), which have a hydroxyl functional group at the 12th carbon. This provides a hydroxyl value of between 160 and $180 \mathrm{mg} \mathrm{KOH} \mathrm{g}^{-1}[4,5]$. However, this low hydroxyl value along with the presence of secondary hydroxyls results in low functionality and low reactivity $[6,7]$, leading to low crosslinking density, which consequently produces semi-flexible and semi-rigid materials among other limitations [8]. Sharma et al. [7] investigated flexible polyurethane foams synthesized partially and completely from castor oil. They showed that foams made from $100 \%$ of castor oil 
were unstable and collapsed indicating the inferior reactivity of castor oil with isocyanate. The modification of castor oil increases its hydroxyl value and hard segment composition to improve the rigidity, physical and mechanical properties and crosslinking density of the final PU products [9]. Nevertheless, the hydroxyl value of modified castor oil is limited.

A renewable and promising source for sustainable chemicals and bio-based polymeric materials is lignin. Its phenylpropanoic structure and high content of diverse functional groups (such as phenolic and aliphatic hydroxyls, carbonyls, carboxyls) allow it to be used as an alternative for polymer development especially in the substitution of petroleum-based polyols in polyurethane synthesis. Many tons of lignin are generated as by-products of industrial processes such as pulp and paper. Most of the lignin extracted from pulp and paper operations is burned during pulp-spent liquor treatment. This offers energy recovery and regeneration of pulping chemicals with less than $2 \%$ recovered for utilization as a chemical product [10]. However, the amount of lignin produced exceeds the requirements for energy generation. The type of pulping process determines the type of lignin industrially available because it unavoidably modifies the lignin structure from that in the original feedstock. To increase the potential applications of lignin in polymeric materials, some chemical modifications have been developed [11, 12], but these add stages to the process and/or raise their costs considerably. Therefore, the direct use of industrial lignin is the most favorable option because it is a relatively cheap raw material. Unmodified lignin has poor stability [13] and difficult melt processing [14], which make its direct use uncompetitive. However, many studies have focused on the incorporation of lignin in polymer materials by blending it with synthetic or other biobased polymers [15-17].

Current studies have shown increasing interest in diversifying the sources of the hydroxyl groups. Mohamed et al. [18] successfully synthetized an ecofriendly waterborne polyurethane dispersion, from castor oil and aromatic polyamide sulfone, via copolymerization reaction. Alternatively, combining lignin and castor oil as polyols for polyurethanic materials is promising. This can produce diversified materials with varied properties and applications. de Oliveira et al. [19] characterized polyurethanic materials based on sulfonated lignin (unmodified and modified by oxypropylation) and castor oil. The DMA results pointed out that the glass transition temperature $\left(T_{\mathrm{g}}\right)$ of the samples increased and thus the degree of crosslinking with the increase of hydroxyl groups derived from different combinations of sulfonated lignin/ sulfonated ligin oxypropylated/castor oil as polyols. Cinelli et al. [20] characterized flexible polyurethanes foams from liquefied lignin and two different chain extenders: castor oil and poly(propylene glycol) (PPG). The single use of unmodified or modified castor oil as a polyol is already consolidated [3,21]. Modified lignins have also been studied for this application [22, 23]. However, the combination of modified castor oil (MCO) and unmodified industrial lignin shows an interesting opportunity for renewable and low cost polyols for preparation of PU.

The aim of this work is to develop and to characterize polyurethane obtained from renewable sources by using polyols including modified castor oil and unmodified paper and pulp residue lignin. The influences of the basic chemistry reactions formed from different combinations were investigated. Fourier transform infrared spectroscopy (FTIR) was used to identify functional groups of the polymers. The thermal and mechanical properties were studied using thermogravimetric analysis (TGA), dynamic mechanical analysis (DMA) and tensile property measurements. Our research efforts focused on the development of novel $100 \%$ renewable polyols able to synthetize polyurethanes with a wide range of glass transition temperature $\left(T_{\mathrm{g}}\right)$ and mechanical properties. The wide range of lignin-containing polyurethane mechanical properties can make it suitable for the replacement of petroleum-based PU on several applications.

\section{Experimental section}

\subsection{Materials}

Technical Kraft lignin (TKL) was obtained as a byproduct of pulp and paper production. It was kindly supplied by Suzano Papel e Celulose (Suzano, SP, Brazil) with the following characteristics: brown color, $M_{\mathrm{w}}=3388 \mathrm{~g} \cdot \mathrm{mol}^{-1}$ (obtained by gel permeation chromatography) $\mathrm{pH} 8.1$, solid content $=92.5 \%$, ashes $=10 \%$ and total hydroxyl index equivalent to 

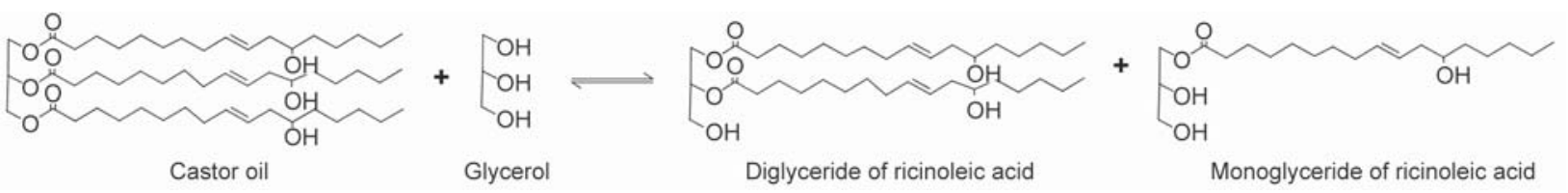

Figure 1. Schematic drawing of castor oil modification reaction

$243 \mathrm{mg} \mathrm{KOH} \mathrm{g}{ }^{-1}$ (determined by ${ }^{31} \mathrm{P}$ nuclear magnetic resonance). The TKL was dried at $80^{\circ} \mathrm{C}$ for $6 \mathrm{~h}$ before polyol preparation.

Castor oil (CO) and two types of modified castor oil (MCO1 and MCO2) were provided by CPA Brazil (Diadema, SP, Brazil) with a hydroxyl index of 159, 237 and $286 \mathrm{mg} \mathrm{KOH} \mathrm{g}^{-1}$ and acid index of $0.95,3.87$ and $4.25 \mathrm{mg} \mathrm{KOH} \mathrm{g}^{-1}$, respectively (determined by titration). $\mathrm{MCO} 1$ and $\mathrm{MCO} 2$ were synthetized using a stainless steel industrial reaction kettle equipped with mechanical stirring, temperature monitoring, cooling control system and $\mathrm{N}_{2}$ inlet. Castor oil was modified by reacting with glycerol and $\mathrm{Ca}(\mathrm{OH})_{2}$ ( $1 \%$ of reactant total mass) at $230^{\circ} \mathrm{C}$ for $8 \mathrm{~h}$. Varying castor oil/glycerol ratios gave modified castor oils with different hydroxyl index. The reaction scheme of castor oil modification is shown in Figure 1.

Diphenylmethane diisocyanate (MDI) was acquired for polyurethane preparation from Kalium Chemical (São Paulo, SP, Brazil). It contained 30 and 32\% (minimum and maximum) NCO group values.

\subsection{Polyurethane preparation}

Natural renewable source lignin-containing polyols were obtained by adding 10, 20 or $30 \mathrm{wt} \%$ of technical Kraft lignin (TKL) with castor oil (CO) or with modified castor oils (MCO1 or MCO2). Lignin-containing polyols were obtained by stirring $50 \mathrm{~g}$ of $\mathrm{CO}$, $\mathrm{MCO} 1$ or $\mathrm{MCO} 2$ and the respective lignin weight ratios. Polyol preparation was carried out under air at room temperature, for $10 \mathrm{~min}$ at $80 \mathrm{rpm}$ in a $200 \mathrm{~mL}$ beaker. Polyurethanes (PU-CO, PU-MCO1 and PU$\mathrm{MCO} 2)$ were prepared by mechanically mixing MDI and the natural renewable source lignin-containing polyols $(\mathrm{NCO} / \mathrm{OH}$ equivalent molar ratio of 1.2$)$ for $2 \mathrm{~min}$ at $20 \mathrm{rpm}$ in a $200 \mathrm{~mL}$ beaker [19]. Polyol compositions are presented in Table 1 .

The mixed polyurethane was poured into the cavities of an open silicon mold, with cavity dimensions according to ASTM D638-10 specimens Type I. The cure was carried out at room temperature for 7 days. Figure 2 shows representative reaction schemes between TKL/MDI/modified castor oil, which elucidates the urethane group formation and consequent polymeric structure.

\subsection{Characterizations}

\subsubsection{Fourier transform infrared spectroscopy (FTIR)}

The spectroscopic measurements in the infrared regions (FTIR) were performed in a Thermo Nicolet Nexus 4700 spectrometer in transmittance mode; 10 scans were performed from $4000-500 \mathrm{~cm}^{-1}$ with a resolution of $4 \mathrm{~cm}^{-1}$ in each sample.

\subsubsection{Thermogravimetric analysis (TG)}

Thermogravimetric analysis (TG) was carried out using Netzsch equipment model STA 449F3. The samples $(11.0 \mathrm{mg})$ were heated from 25 to $800^{\circ} \mathrm{C}$ under nitrogen atmosphere and $50 \mathrm{~mL} \cdot \mathrm{min}^{-1}$ flow and a heating rate of $10^{\circ} \mathrm{C} \cdot \mathrm{min}^{-1}$.

Table 1. Nomenclature and compositions of developed polyols according to TKL and oil $\mathrm{wt} \%$

\begin{tabular}{|l|c|c|c|c|}
\hline & PU-CO & PU-CO/L10 & PU-CO/L20 & PU-CO/L30 \\
\hline TKL $[\mathrm{wt} \%]$ & 0 & 10 & 20 & 30 \\
\hline CO $[\mathrm{wt} \%]$ & 100 & 90 & 80 & PU-MCO1/L30 \\
\hline & PU-MCO1 & PU-MCO1/L10 & PU-MCO1/L20 & 30 \\
\hline TKL $[\mathrm{wt} \%]$ & 0 & 10 & 20 & 70 \\
\hline MCO1 $[\mathrm{wt} \%]$ & 100 & 90 & PU-MCO2/L20 & PU-MCO2/L30 \\
\hline & PU-MCO2 & PU-MCO2/L10 & 20 & 30 \\
\hline TKL $[\mathrm{wt} \%]$ & 0 & 10 & 80 & 70 \\
\hline MCO2 $[\mathrm{wt} \%]$ & 100 & 90 & & \\
\hline
\end{tabular}



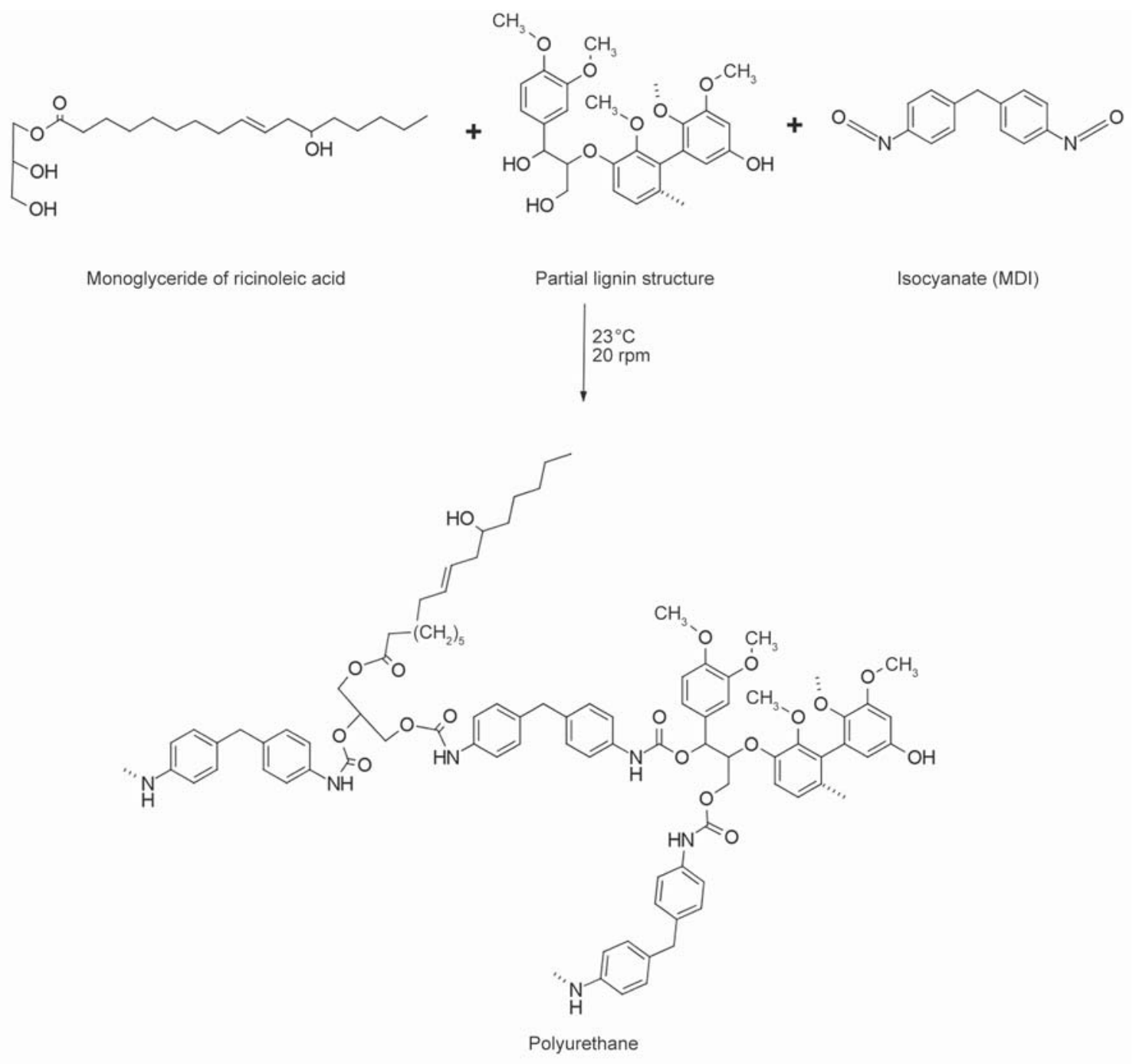

Figure 2. Schematic drawing of polyurethane groups formation from TKL/MDI/MCO reaction

\subsubsection{Dynamic mechanical analysis (DMA)}

Glass transition temperature $\left(T_{\mathrm{g}}\right)$ of renewable polyol based polyurethanes was investigated by DMA using a thermal analyzer model Pyris Diamond, Perkin Elmer. Measurements were carried out in flexural mode (single cantilever) with a temperature range from -50 to $150^{\circ} \mathrm{C}$, frequency of $1 \mathrm{~Hz}$, oscillation amplitude of $10 \mathrm{~mm}$ and heating rate of $2^{\circ} \mathrm{C} \cdot \mathrm{min}^{-1}$. The dimension of specimens was $30 \mathrm{~mm} \times 12 \mathrm{~mm} \times$ $2 \mathrm{~mm}$, which were obtained by casting PU into the cavities of an open silicon mold. Storage modulus at rubbery plateau $\left(E_{\mathrm{R}}^{\prime}\right)$ was used to calculate crosslinking density.

\subsubsection{Mechanical properties}

The mechanical properties (5 specimens for each condition) were tested according to ASTM D638 with
Type I test specimens using an Instron universal testing machine model 5569 (CECS, Federal University of ABC, Santo André, SP, Brazil) with a crosshead speed of $50 \mathrm{~mm} \cdot \mathrm{min}^{-1}$ and a non-contact extensometer (Instron SVE). Type I test specimens presented following dimensions: overall length $(165 \mathrm{~mm})$, width of narrow section $(13 \mathrm{~mm})$, overall thickness $(5 \mathrm{~mm})$ and gage length $(50 \mathrm{~mm})$.

\subsubsection{Scanning electron microscopy (SEM)}

After mechanical testing, SEM was used to observe the cross sectional morphology of the fractured surfaces of the samples using a Jeol 6460LV scanning electron microscope with an electron beam at an accelerating voltage of $25 \mathrm{kV}$. The samples were set on the SEM sample holder and sputter coated with a thin layer of gold. 


\section{Results and discussion}

\subsection{Fourier transform infrared spectroscopy (FTIR)}

Figure 3 shows the FTIR analysis for $\mathrm{CO}, \mathrm{MCO} 1$ and $\mathrm{MCO} 2$ oils. All spectra present the characteristic peak at $3400 \mathrm{~cm}^{-1}$. This corresponds to the hydroxyl group. $\mathrm{MCO} 1$ and $\mathrm{MCO} 2$ show increase in this band intensity (Figure 3b), which is related to hydroxyl value increasing after modification. Other characteristic absorption bands are observed at $2920 \mathrm{~cm}^{-1}$ (methyl), $2850 \mathrm{~cm}^{-1}$ (methylene), $1740 \mathrm{~cm}^{-1}$ (esters) and $1161 \mathrm{~cm}^{-1}(\mathrm{C}-\mathrm{O}-\mathrm{C})$ [23-26].

Figure 4 compares the FTIR spectra of PU-CO, PU$\mathrm{MCO} 1$ and PU-MCO2. A characteristic band of urethane stretching at $3330 \mathrm{~cm}^{-1}$ is present on all samples, which corresponds to hydrogen bonded $\mathrm{N}-\mathrm{H}$ group in disordered form [19, 24]. The increasing intensity of this band (Figure 4b) shows the increased amount of urethane groups for PU-MCO1 and PU$\mathrm{MCO}$, which might be associated with reaction of $\mathrm{NCO}$ with increased hydroxyl level of MCO1 and

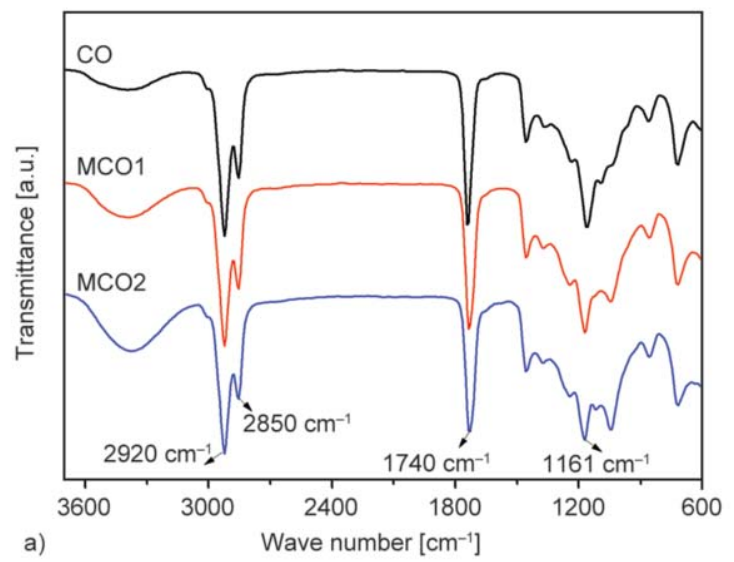

$\mathrm{MCO} 2$. The absence of NCO stretching at $2260 \mathrm{~cm}^{-1}$ indicates that the isocyanate groups have been entirely reacted [19, 24, 27]. Other main absorption bands confirm polyurethane formation including absorptions in the region between $1704-1709 \mathrm{~cm}^{-1}$ (carbonyl group hydrogen bonding to the urethane group) and $1215 \mathrm{~cm}^{-1}$ (urethane linkages) [19, 23, 27].

Figure 5 shows the FTIR spectra of lignin-containing polyurethanes (varying the TKL wt $\%$ into the polyurethanes) and of TKL (Figure 5b, 5d and 5f). The band at $3425 \mathrm{~cm}^{-1}$, TKL spectrum (Figure $5 \mathrm{~b}, 5 \mathrm{~d}$ and $5 \mathrm{f}$ ), is characteristic of its aromatic and aliphatic $\mathrm{OH}$ bond stretching $[15,28,29]$. The presence of lignin in polyurethane resulted into the formation of a wider band in the $3330-3425 \mathrm{~cm}^{-1}$ region due to merging of the bonded $\mathrm{NH}$ band $\left(3330 \mathrm{~cm}^{-1}\right)$ with lignin $\mathrm{OH}$ bond stretching $\left(3425 \mathrm{~cm}^{-1}\right)$ [27]. It can be observed in parts $b, d$ and $f$ of Figure 5 that the intensity of the merged region increases with the increasing of lignin quantity for all samples.

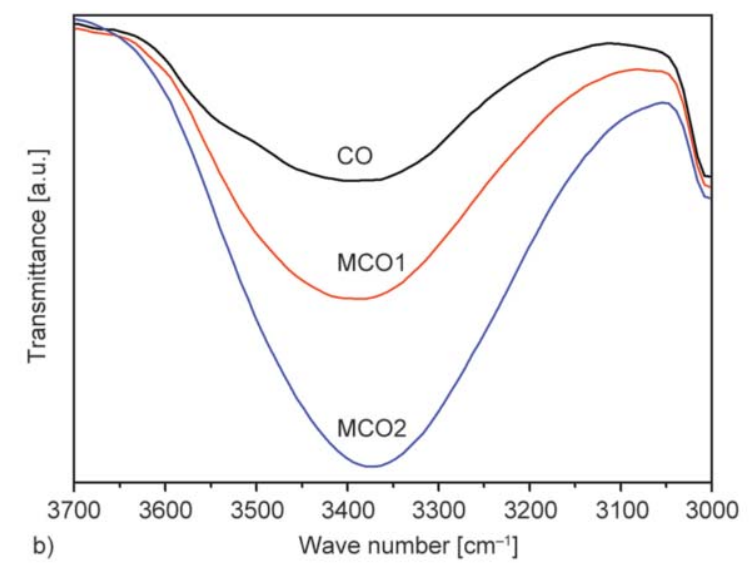

Figure 3. FTIR spectra of vegetable oils (CO, MCO1 and MCO2) (a) from 3700 to $600 \mathrm{~cm}^{-1}$ and (b) from 3700 to $3000 \mathrm{~cm}^{-1}$
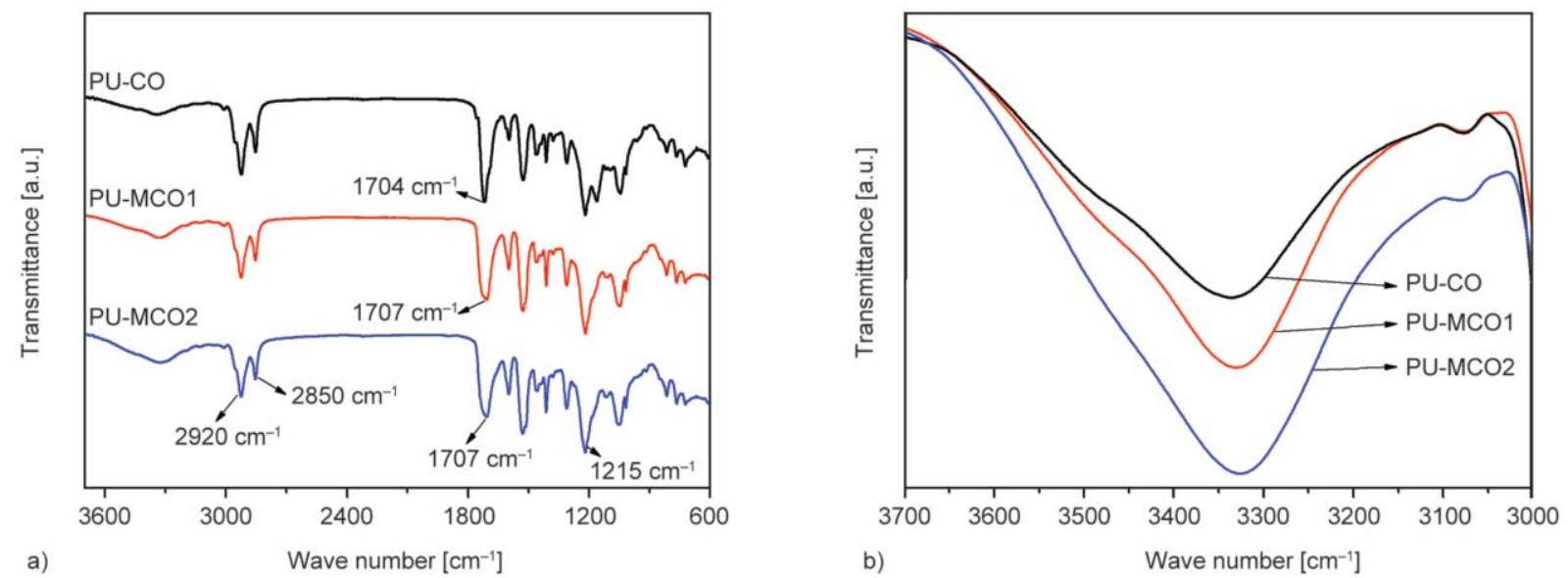

Figure 4. FTIR spectra of PU-CO, PU-MCO1 and PU-MCO2 (a) from 3700 to $600 \mathrm{~cm}^{-1}$ and (b) from 3700 to $3000 \mathrm{~cm}^{-1}$ 

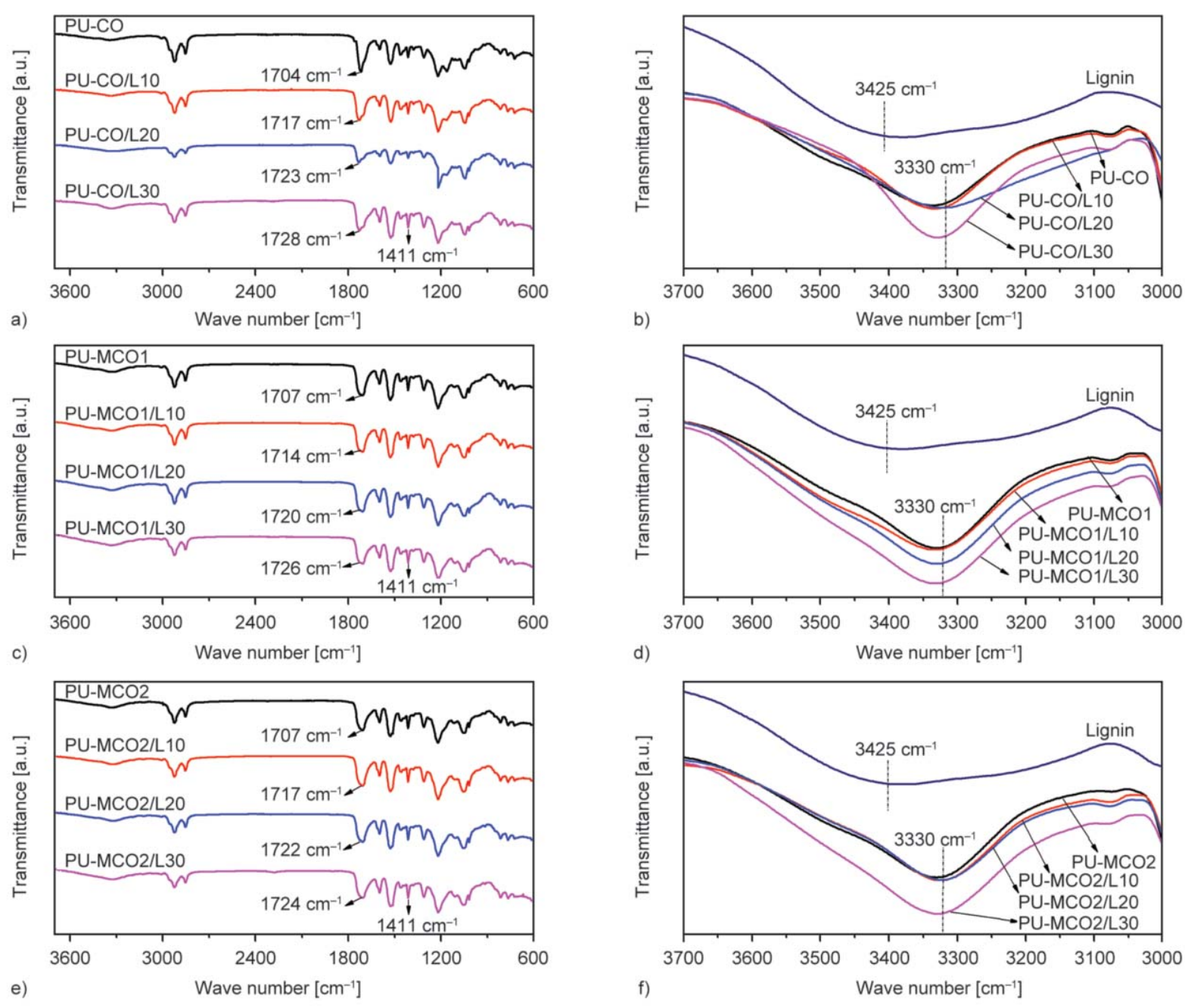

Figure 5. FTIR spectra of PU-CO/lignin compositions (a) from 3700 to $600 \mathrm{~cm}^{-1}$, (b) PU-CO/lignin and lignin (TKL) from 3700 to $3000 \mathrm{~cm}^{-1}$; of PU-MCO1/lignin compositions, (c) from 3700 to $600 \mathrm{~cm}^{-1}$, (d) PU-CO1/lignin and lignin (TKL) from 3700 to $3000 \mathrm{~cm}^{-1}$; and PU-MCO2/lignin (e) from 3700 to $600 \mathrm{~cm}^{-1}$, (f) PU-CO2/lignin and lignin (TKL) from 3700 to $3000 \mathrm{~cm}^{-1}$

As can be seen in Figures 5a, 5c and 5e the spectra of lignin-containing polyurethanes show that as the lignin content increases, the peak of the carbonyl stretching vibration (around $1700 \mathrm{~cm}^{-1}$ ) gradually shifted to higher wavenumbers. Carbonyl bands of polyurethane can be divided on three main regions: the hydrogen bonded carbonyl in ordered crystalline domains at $1700-1709 \mathrm{~cm}^{-1}[19,24,27]$, the hydrogen bonded carbonyl in disordered amorphous conformations at $1714-1720 \mathrm{~cm}^{-1}[19,30]$ and the free carbonyl groups (non bonded) at 1731-1745 $\mathrm{cm}^{-1}$ $[23,31]$. The carbonyl band shifting indicates that the presence of lignin induces the change from a hydrogen bonded ordered crystalline domain (PU-CO, PUMCO1 and PU-MCO2) to a disordered amorphous conformation and to the formation of free carbonyl groups (PU-CO/lignin, PU-MCO1/lignin and PU-
MCO2/lignin) [27]. The absence of NCO stretching at $2260 \mathrm{~cm}^{-1}$ in all lignin-containing polyurethane spectra indicates that the isocyanate groups have been entirely reacted $[19,24,27]$.

\subsection{Thermogravimetric analysis (TGA)}

The TGA and derivative TG curves for castor oilbased PU and castor oil/lignin-based PU are presented in Figures 6 and 7. The stability of the PU is related to the hard segment nature (rigid aromatic ring of MDI and TKL), soft segment (introduced by flexible chains of castor oil) and the molar ratio of the hard segment to soft segment [32]. In general, the thermal degradation of polyurethane occurs in a two to three steps, and the composition of the decomposed products depends on the structure of the PU material [33]. 

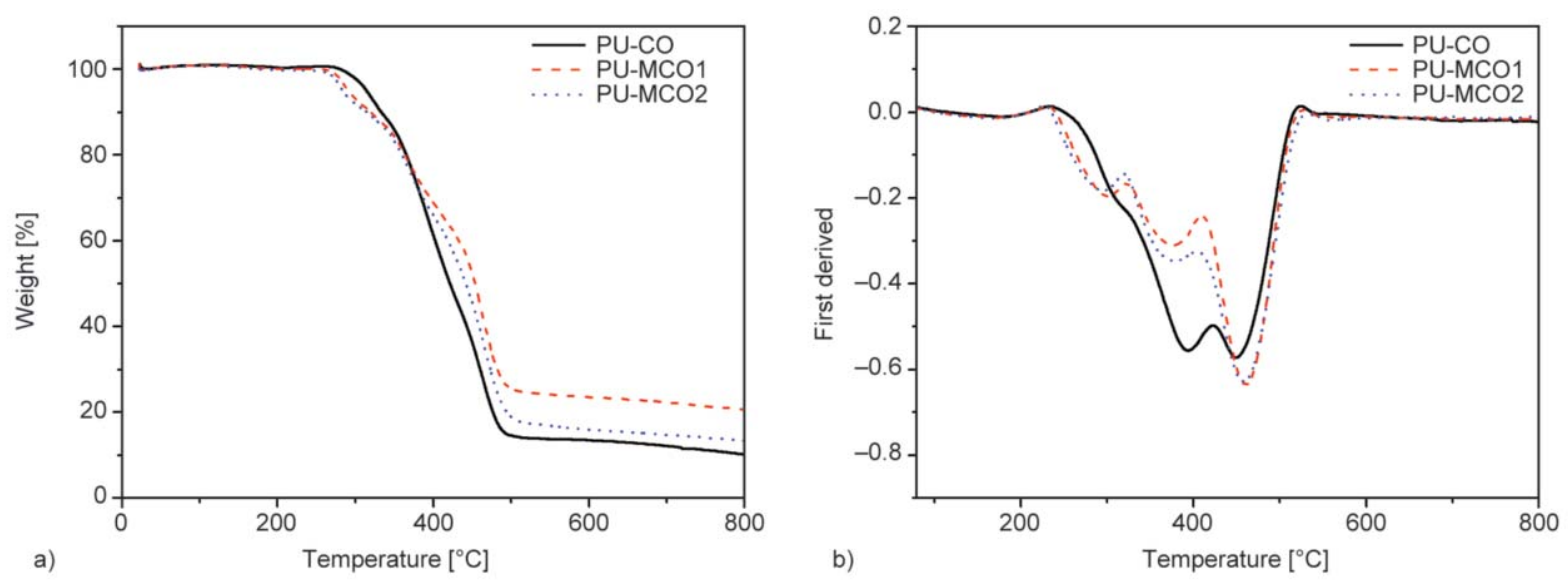

Figure 6. (a) TGA curves of PU-CO, PU-MCO1 and PU-MCO2 and (b) DTG curves of PU-CO, PU-MCO1 and PU-MCO2
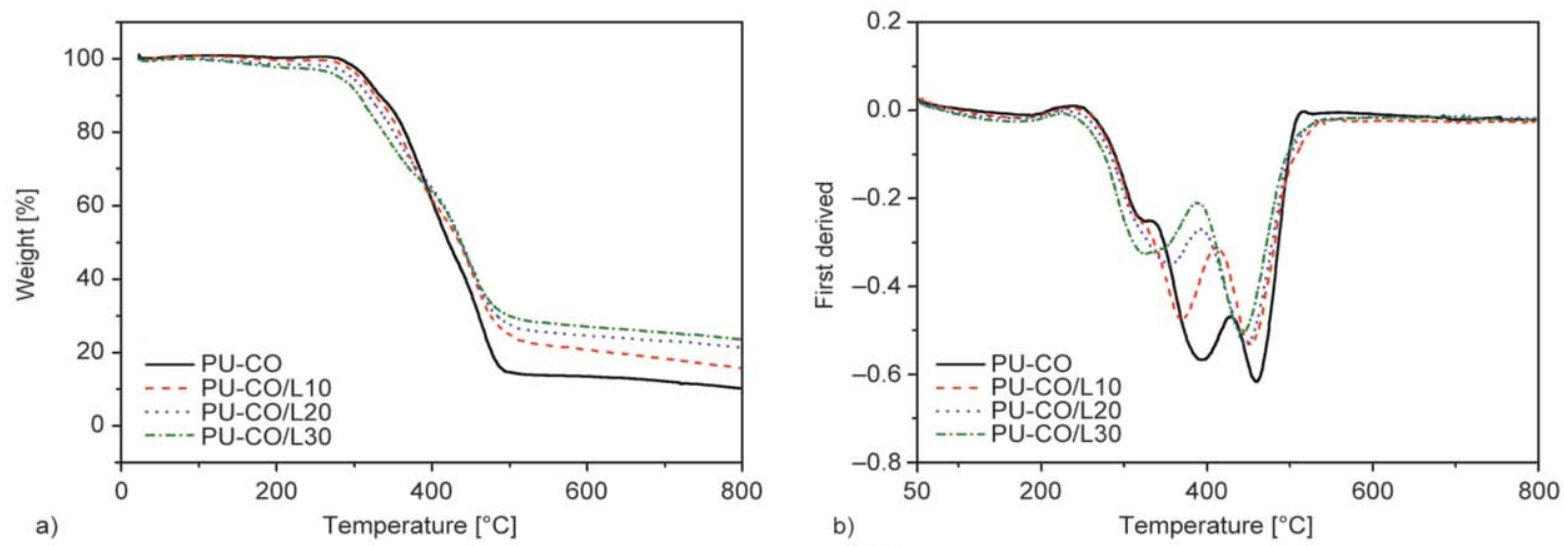

a)

Temperature $\left[{ }^{\circ} \mathrm{C}\right]$
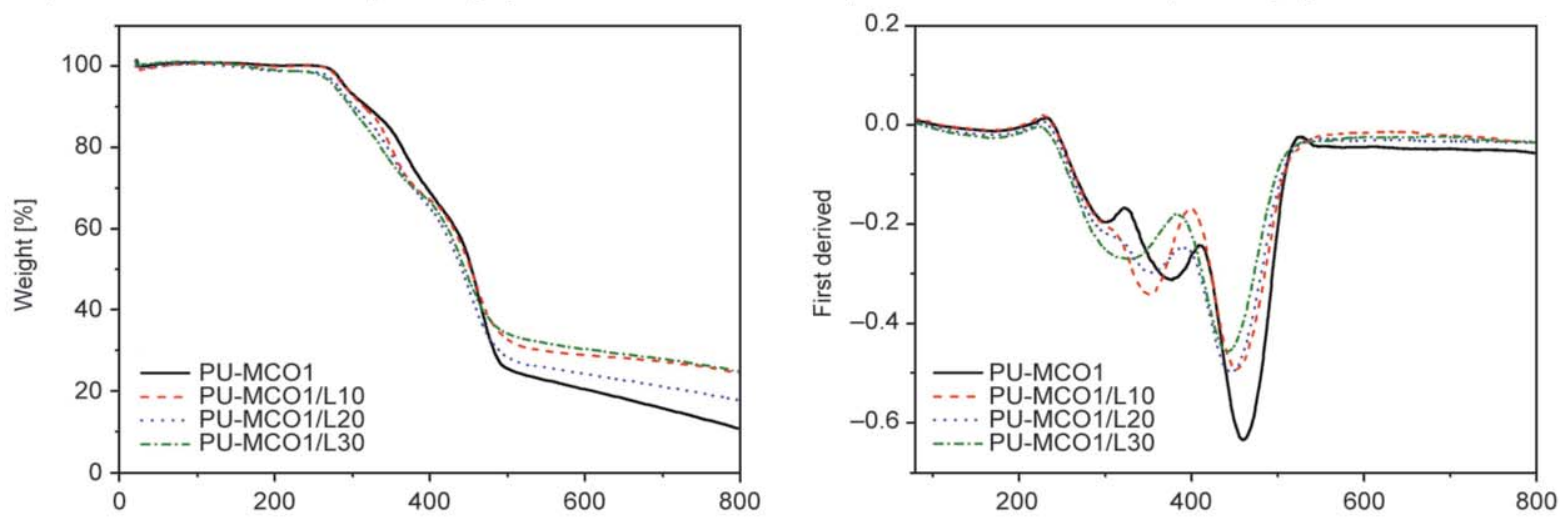

c)

Temperature $\left[{ }^{\circ} \mathrm{C}\right]$
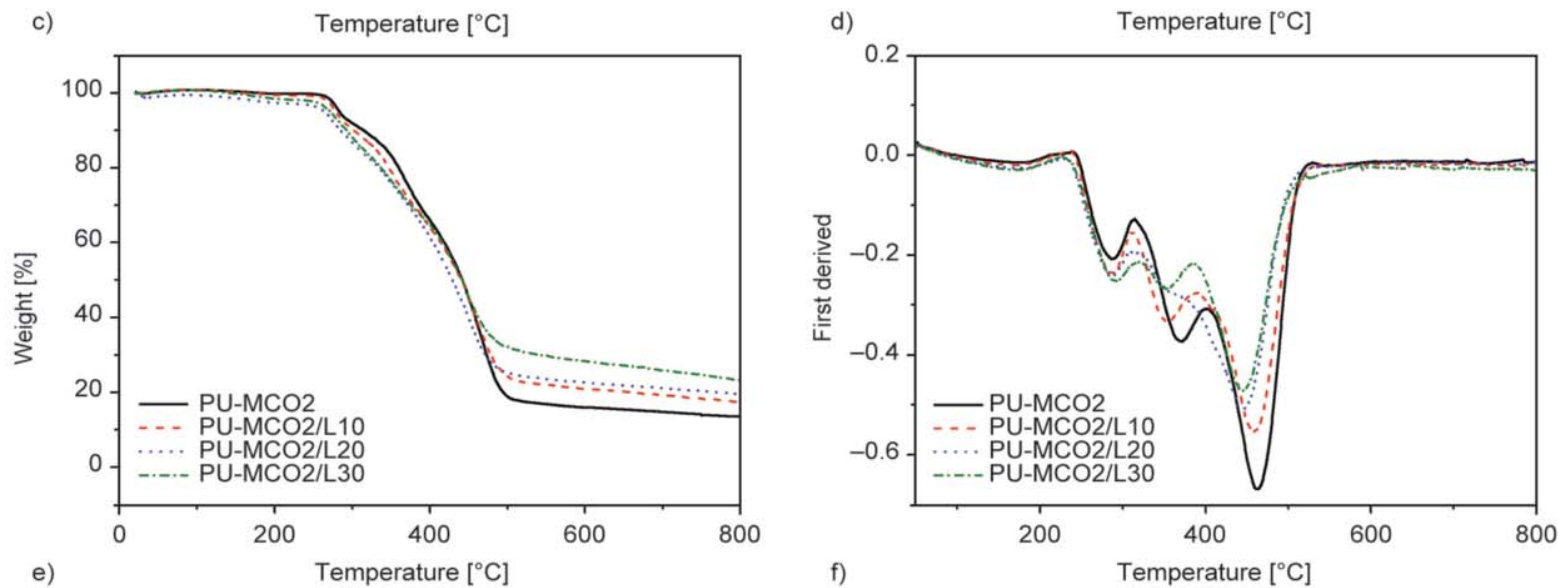

Figure 7. (a) TGA curves of PU-CO and PU-CO/lignin, (b) DTG curves of PU-CO and PU-CO/lignin, (c) TGA curves of PU-MCO1 and PU-MCO1/lignin, (d) DTG curves of PU-MCO1 and PU-MCO1/lignin, (e) TGA curves of PUMCO2 and PU-MCO2/lignin and (f) DTG curves of PU-MCO2 and PU-MCO2/lignin compositions 
A first step decomposition is observed around $270^{\circ} \mathrm{C}$ and is related to the thermal decomposition of unstable urethane bonds [27]. The second step occurs above $320^{\circ} \mathrm{C}$. The mass loss occurs at a fast rate in this step. It is associated to the soft segment and depends on its structure and three-dimensional arrangement [33]. The third one is above $380^{\circ} \mathrm{C}$ and is also related to other remaining structures formed after the second decomposition, diisocyanate and lignin aromatic rings $[1,25,34]$.

Figure 6 shows the TGA and derivative curves of PU-CO, PU-MCO1 and PU-MCO2, respectively. The PU-MCO2 and PU-MCO1 showed lower degradation temperature for first step decomposition (maximum peaks at 289.3 and $294.2^{\circ} \mathrm{C}$, respectively) and presented higher mass loss compared to $\mathrm{PU}-\mathrm{CO}$ $\left(320.0^{\circ} \mathrm{C}\right)$ due to increasing urethane groups that were improved by castor oil modification. The second step decomposition may correspond to the chain scission of CO (PU-CO $393.6^{\circ} \mathrm{C}$, PU-MCO1 $372.3^{\circ} \mathrm{C}$, and PU-MCO2 $370.9^{\circ} \mathrm{C}$ ), the soft polyurethane segment, also observed by Hablot et al. [35]. In the third step of decomposition, DTG peaks are shown at $448.5^{\circ} \mathrm{C}$ for PU-CO, $457.1^{\circ} \mathrm{C}$ for PU-MCO1, and $459.4^{\circ} \mathrm{C}$ for PU-MCO2.

Figure 7 shows TGA and DTG curves of PU-CO/ lignin, PU-MCO1/lignin and PU-MCO2/lignin compositions. The presence of lignin for all conditions decreased the onset of thermal decomposition. The degradation onset in the $250-290{ }^{\circ} \mathrm{C}$ temperature range corresponds to the decomposition of unstable urethane bond from hard segment, but also the cleavage of unstable ether linkages of lignin (Figure 7a, $7 \mathrm{c}$ and 7e) [23]. Derivative curves for PU-CO/L20, $\mathrm{PU}-\mathrm{CO} / \mathrm{L} 30$ and PU-MCO1/L30 revealed two decomposition peaks, as can be seen in Figure $7 \mathrm{~b}$ and $7 \mathrm{~d}$. The two first stages, hard and soft segment degradations, became close resulting in one larger peak, also observed by Zhang et al. [23]. The larger peaks have shifted to lower temperature and smaller intensity, compared to the second step decomposition of lignin free polyurethane, at $300-400^{\circ} \mathrm{C}$ range. Lignin incorporation did not significantly affect the degradation behavior but it rather increased the amount of char formation, observed in TGA curves above $500^{\circ} \mathrm{C}$. It was found that the char residue of lignincontaining polyurethanes increases as the lignin concentration increases. Table 2 presents additional ther-
Table 2. Thermogravimetric parameters of PU-CO/lignin, PU-MCO1/lignin and PU-MCO2/lignin

\begin{tabular}{|l|c|c|c|c|}
\hline & $\begin{array}{c}\boldsymbol{T}_{\text {onset }} \\
{\left[{ }^{\circ} \mathbf{C}\right]}\end{array}$ & $\begin{array}{c}\boldsymbol{T}_{\mathbf{5 0}} \% \\
{\left[{ }^{\circ} \mathbf{C}\right]}\end{array}$ & $\begin{array}{c}\boldsymbol{T}_{\text {offset }} \\
{\left[{ }^{\circ} \mathbf{C}\right]}\end{array}$ & $\begin{array}{c}\text { Char residue } \\
{[\mathbf{\%}]}\end{array}$ \\
\hline PU-CO & 290.7 & 421.5 & 484.6 & 11.2 \\
\hline PU-CO/L10 & 287.7 & 434.8 & 485.9 & 17.0 \\
\hline PU-CO/L20 & 284.2 & 438.1 & 480.9 & 22.2 \\
\hline PU-CO/L30 & 282.3 & 437.2 & 478.8 & 24.6 \\
\hline PU-MCO1 & 267.1 & 453.7 & 486.3 & 13.3 \\
\hline PU-MCO1/L10 & 265.6 & 452.6 & 487.9 & 19.5 \\
\hline PU-MCO1/L20 & 264.8 & 440.9 & 486.3 & 26.1 \\
\hline PU-MCO1/L30 & 264.3 & 444.9 & 477.8 & 26.5 \\
\hline PU-MCO2 & 267.3 & 441.8 & 492.6 & 13.9 \\
\hline PU-MCO2/L10 & 263.6 & 440.9 & 488.7 & 18.4 \\
\hline PU-MCO2/L20 & 258.0 & 429.0 & 480.3 & 20.3 \\
\hline PU-MCO2/L30 & 259.9 & 441.5 & 485.5 & 24.6 \\
\hline
\end{tabular}

mogravimetric parameters, including initial decomposition temperature for degradation step ( $\left.T_{\text {onset }}\right)$, final decomposition temperature for degradation step $\left(T_{\text {offset }}\right)$, temperature for $50 \%$ mass loss $\left(T_{50 \%}\right)$ and $\%$ mass of remaining char at $750{ }^{\circ} \mathrm{C}$.

\subsection{Dynamic mechanical analysis (DMA)}

The evolution of $\tan \delta$ as function of temperature is presented in Figure 8 and might be attributed to the glass transition temperature $\left(T_{\mathrm{g}}\right)$ [23]. A wide $T_{\mathrm{g}}$ range might be obtained for polyurethanes, which is dependent on polymer segment, hard and soft nature, and composition [19].

Figure 8a shows the glass transition temperature of $\mathrm{PU}-\mathrm{CO}$ and $\mathrm{PU}-\mathrm{CO} /$ lignin conditions. Tan $\delta$ values shifted to higher temperature as $\mathrm{TKL} w \mathrm{t} \%$ increases. PU-CO presented the $T_{\mathrm{g}}$ at $-0.76^{\circ} \mathrm{C}$ and is mainly related to soft segments [19]. Increasing lignin content shifted the $T_{\mathrm{g}}$ to a maximum value of $47.5^{\circ} \mathrm{C}$ for PU-CO/L30, mainly due to lignin rigid segment movements [19]. Lignin mass percentage and $T_{\mathrm{g}}$ shifting presented a linear dependence. Lignin mass fraction increasing also induced the $\tan \delta$ peak broadening, which implies in the sample heterogeneity and might be related to augment of molecular weight of polyol component [36]. In this study, it might have been induced by high molecular weight and heterogeneous molecular structure of TKL added.

Tan $\delta$ curves of PU-MCO1 and PU-MCO 2 based polyurethanes are presented in Figures $8 \mathrm{~b}$ and $8 \mathrm{c}$. As general tendency, the $T_{\mathrm{g}}$ shifted to higher temperatures as TKL content increased. It can be seen in Figures $8 \mathrm{a}, 8 \mathrm{~b}$ and $8 \mathrm{c}$ that all lignin-containing polyure- 

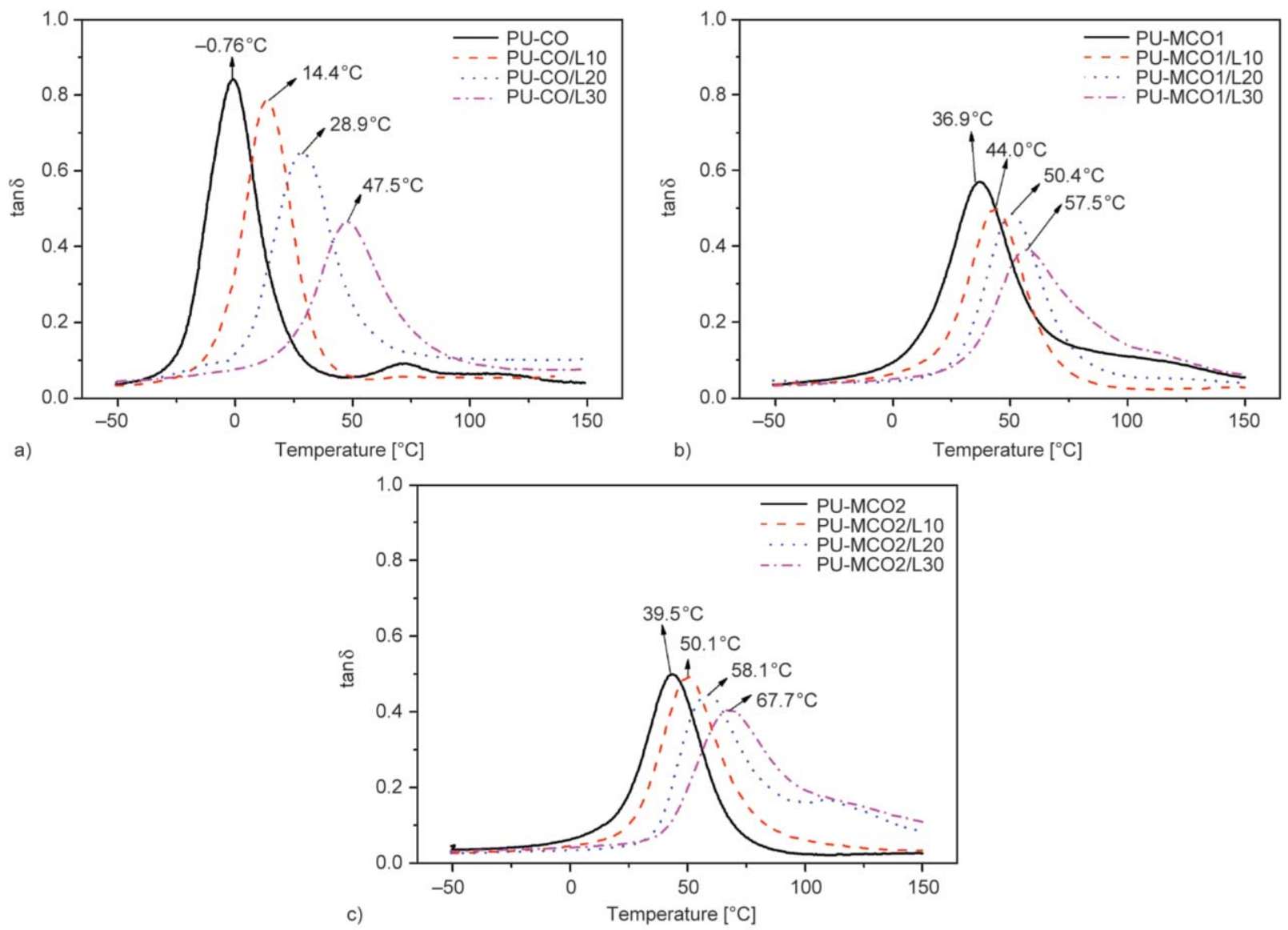

Figure 8. DMA curves ( $\tan \delta$ ) of (a) PU-CO/lignin, (b) PU-MCO1/lignin and (c) PU-MCO2/lignin

thanes show a single $\tan \delta$ peak, which is an indicative of polyol components miscibility. PU-CO is the only condition that presented a small secondary peak, which might be associated to a slight phase separation between soft and hard segments in this composition.

It is of interest to evaluate the effects of CO modification and TKL addition on polyurethane crosslinking density $(v)$, which can be calculated using storage modulus at rubbery plateau [36]. The crosslinking density can be obtained, for samples submitted to normal stress (tensile and flexural operation mode), Equation (1) [37]:

$v=\frac{E_{\mathrm{R}}^{\prime}}{3 R T}$

where $R$ is the gas constant, $E_{\mathrm{R}}^{\prime}$ is the storage modulus at rubbery plateau and $T$ the absolute temperature. Storage modulus at rubbery plateau and calculated crosslinking density are presented in Table 3 . Castor oil modification increased polyurethane crosslinking density from $293 \mathrm{~mol} \cdot \mathrm{m}^{-3}$ (PU-CO) to

Table 3. Storage modulus at rubbery plateau and crosslinking density of PU-CO/lignin, PU-MCO1/lignin and PUMCO2/lignin

\begin{tabular}{|l|c|c|c|c|}
\hline & PU-CO & PU-CO/L10 & PU-CO/L20 & PU-CO/L30 \\
\hline$E_{\mathrm{R}}^{\prime}[\mathrm{MPa}]$ & 2.5 & 6.1 & 6.9 & 13.2 \\
\hline$v\left[\mathrm{~mol} \cdot \mathrm{m}^{-3}\right]$ & 293 & 670 & 731 & 1360 \\
\hline & PU-MCO1 & PU-MCO1/L10 & PU-MCO1/L20 & PU-MCO1/L30 \\
\hline$E_{\mathrm{R}}^{\prime}[\mathrm{MPa}]$ & 3.2 & 13.4 & 19.1 & 22.4 \\
\hline$v\left[\mathrm{~mol} \cdot \mathrm{m}^{-3}\right]$ & 331 & 1365 & 1919 & 2209 \\
\hline & PU-MCO2 & PU-MCO2/L10 & PU-MCO2/L20 & PU-MCO2/L30 \\
\hline$E_{\mathrm{R}}^{\prime}[\mathrm{MPa}]$ & 5.4 & 9.1 & 13.1 & 14.6 \\
\hline$v\left[\mathrm{~mol} \cdot \mathrm{m}^{-3}\right]$ & 560 & 918 & 1288 & 1407 \\
\hline
\end{tabular}


$560 \mathrm{~mol} \cdot \mathrm{m}^{-3}$ (PU-MCO2). The crosslinking density increasing of PU-CO/lignin, PU-MCO1/lignin and $\mathrm{PU}-\mathrm{MCO} 2 /$ lignin is a direct response of TKL wt $\%$ rising. However, PU-MCO1/lignin presented higher crosslinking density than PU-MCO2/lignin, besides the higher crosslinking density value for PU-MCO2 in comparison to PU-MCO1.

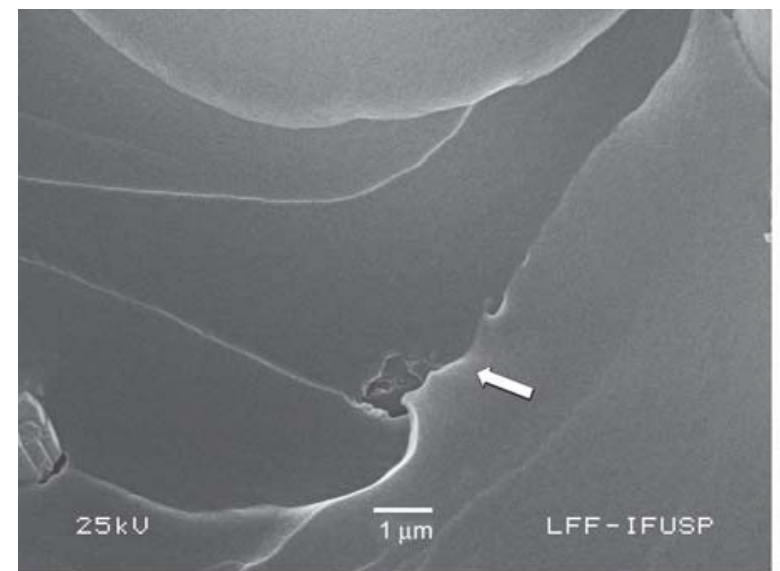

a) $\mathrm{PU}-\mathrm{CO} / \mathrm{L} 20$

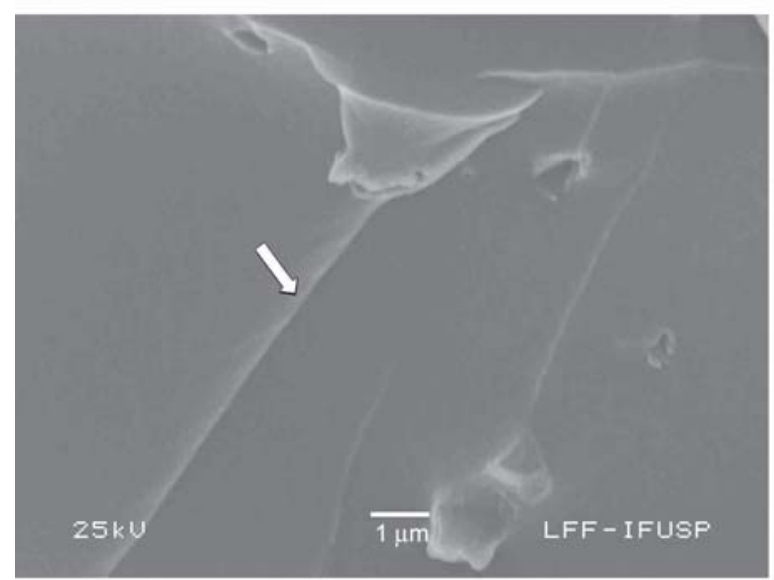

c)

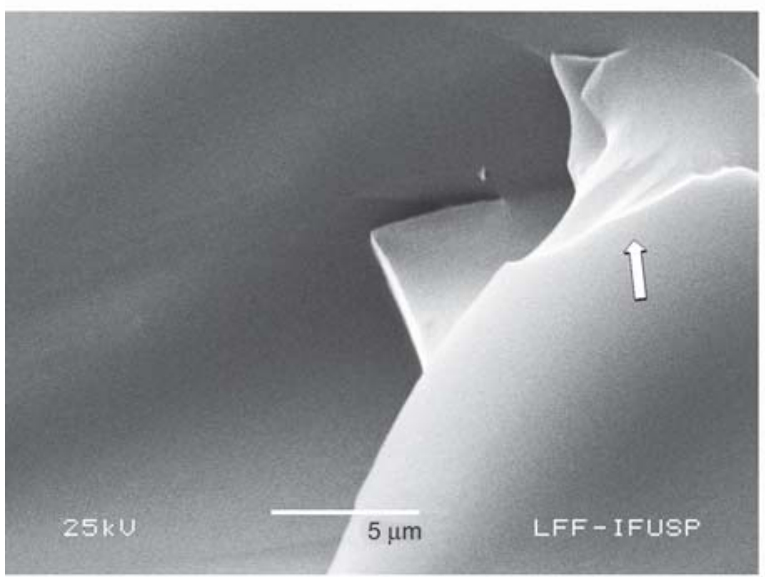

e) $\quad \mathrm{PU}-\mathrm{MCO} 2$

\subsection{Scanning electron microscopy (SEM)}

Lignin-containing PU-COs presented a smooth transition from a ductile fracture (smooth grooves, white arrows) to a brittle one (sharp surfaces, black arrows) [38] near the TKL concentration value of $30 \mathrm{wt} \%$, as illustrate in Figure 9a and 9b; for the PU-MCO1, there is a change in fracture mechanism at $20 \mathrm{wt} \%$

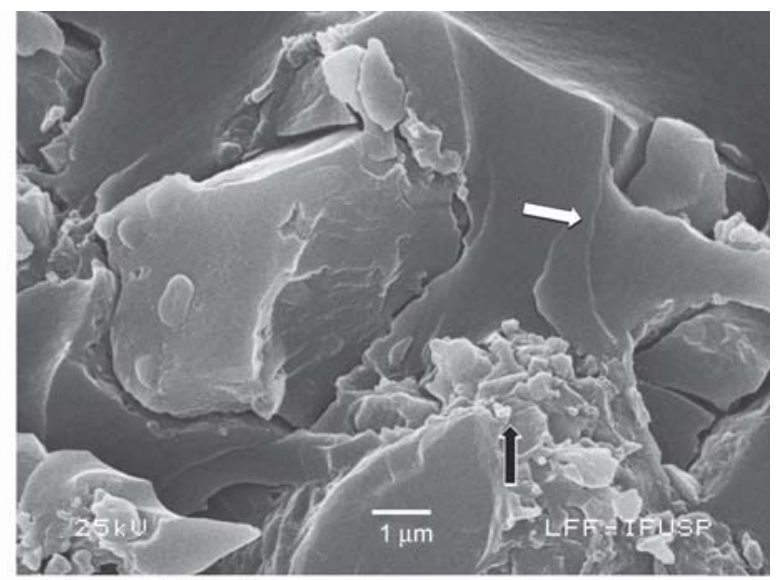

b) $\mathrm{PU}-\mathrm{CO} / \mathrm{L} 30$

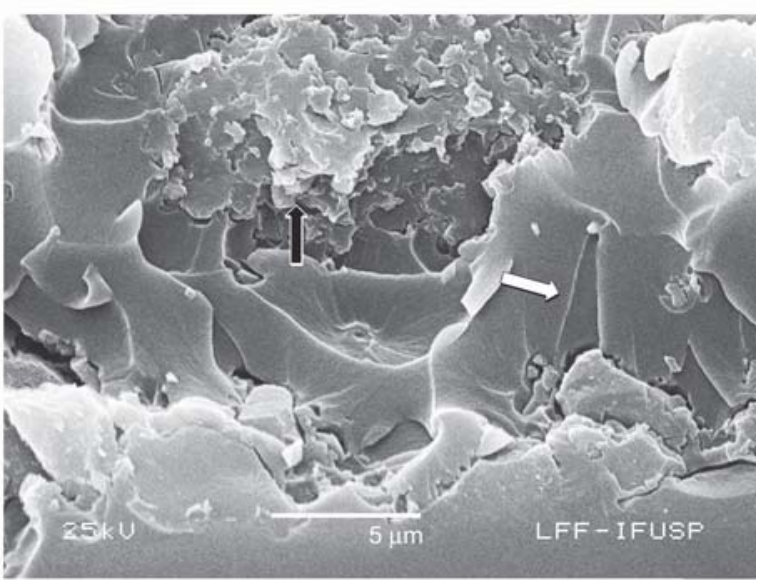

d) PU-MCO1/L20

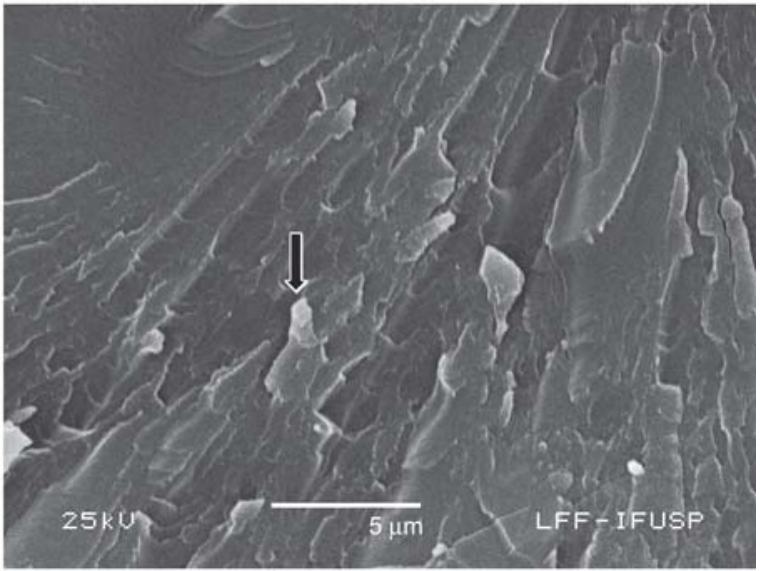

f) $\mathrm{PU}-\mathrm{MCO} 2 / \mathrm{L} 10$

Figure 9. SEM images of the fractured surface of the lignopolyurethanes with magnification of $10000 \times(a, b$ and $c)$ and $5000 \times(d, e$ and $\mathrm{f})$ 
TKL content (Figure 9c and 9d). This behavior is similar for PU-MCO2, where the value is $10 \mathrm{wt} \%$ lignin content (Figure 9e and 9f). It reveals that for PUMCO1 and PU-MCO2 this behavior is anticipated due to lower lignin content.

\subsection{Mechanical properties}

Figure 10 summarizes the mechanical behavior of the polyurethanes. First, the increased hydroxyl index from $\mathrm{CO}$ to $\mathrm{MCO} 1$ and $\mathrm{MCO} 2$ substantially increased the ultimate tensile stress (Figure 10a) and the Young modulus (Figure 10c) of PU-MCO1 and PU-MCO2 versus PU-CO. Polyurethane mechanical behavior is mainly determined by the crosslinking density given by the functionality of its reactants and the stoichiometry between them $[11,39]$.

Figures $10 \mathrm{~b}$ and $10 \mathrm{~d}$ allow analyzing the effects of increasing hydroxyl index on strain. Higher hydroxyl indices decreased elastic strain (Figure 10d), which might be associated to higher amounts of rigid segments and higher crosslinking density in the polymer structure [11, 24]. Comparison of Figure 10b and $10 \mathrm{~d}$ highlights the presence of plastic deformation in PU-CO, PU-MCO1 and PU-MCO2 before rupture. Considering that plastic deformation of ther-
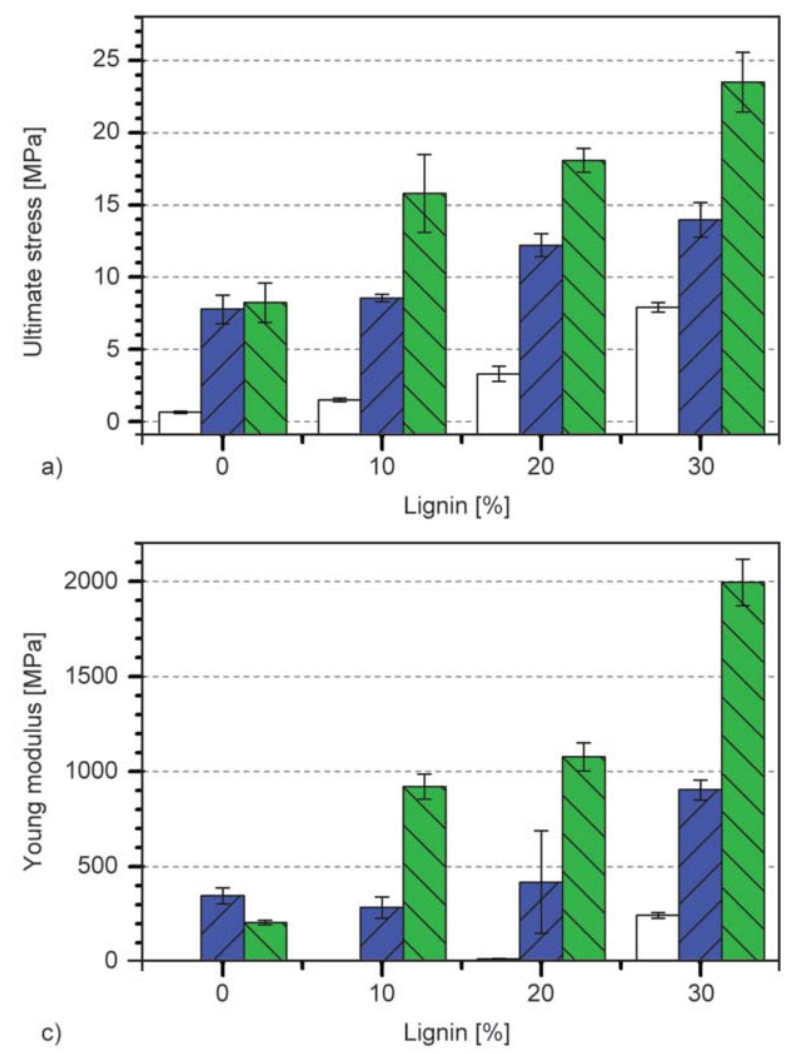

mosets starts after chain scission and is not governed by the crosslinking density [40, 41], a comparison of the increasing hydroxyl index and the ultimate strain is not feasible.

The introduction of TKL in the polyol strongly affected the mechanical behavior and increases the ultimate tensile stress (Figure 10a) and Young's modulus (Figure 10c) of lignin-containing polyurethanes. The maximum tensile stress was $23.50 \mathrm{MPa}$, and the maximum Young's modulus was $2.00 \mathrm{GPa}$ for PU$\mathrm{MCO} / \mathrm{L} 30$. The hardening effect caused by introduction of TKL might be elucidated by two mechanisms: i) Besides its participation as a co-monomer, lignin has a reinforcement role derived from its characteristics (aromatic rigid structure and Young's modulus between 2.31-4.65 GPa) [20, 39, 42, 43]; ii) Crosslinking density increasing [11, 20, 44].

The ultimate strain for PU-CO and PU-MCO1 increased by adding TKL up to 20 and $10 \mathrm{wt} \%$, respectively. As TKL weight contents rises for these compositions, the ultimate strain decreases. This ultimate strain trend inversion converges to ductile-to-brittle transition, as shown in Figure 9, and is related to more rigid segments and consequently to glass transition temperature shifting. The ductile-to-brittle transition

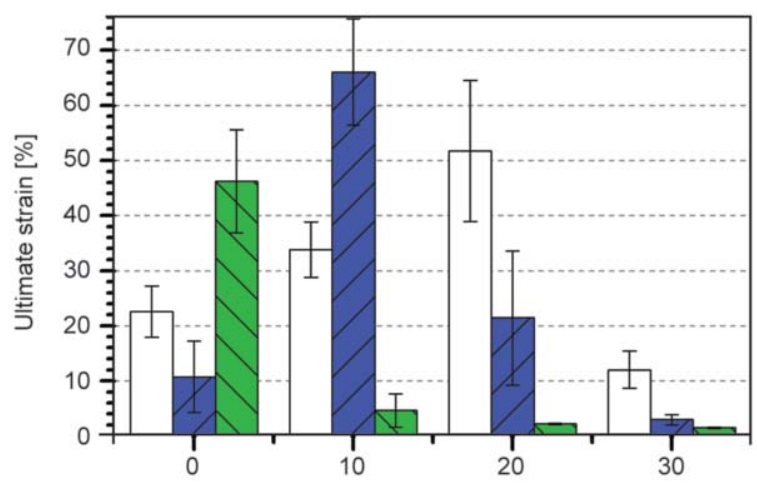

b)

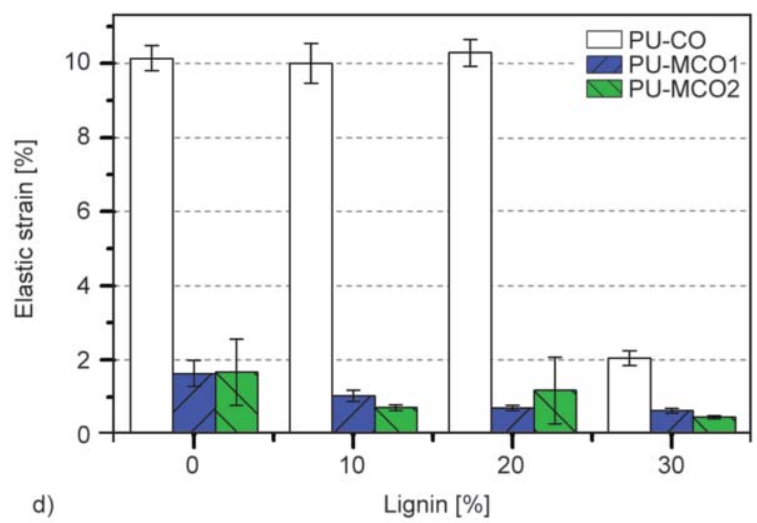

Figure 10. Mechanical results of samples with different amounts of lignin: (a) ultimate stress, (b) ultimate strain, (c) Young modulus and (d) elastic strain 
occurred around $45^{\circ} \mathrm{C}$ for lignin-containing polyurethanes, based on $\mathrm{CO}$ or MCOs, as can be observed in DMA results.

Results pointed out that the mechanical properties of lignin-containing polyurethane are in agreement with the mechanical properties of petroleum based polyurethanes, such as polyurethane adhesives (Young modulus: 0.73 to $2.25 \mathrm{MPa}$; ultimate tensile stress: 17.84 to $40.03 \mathrm{MPa}$ ) $[45,46]$ and crosslinked polyurethanes (typical ultimate tensile stress: 1.70 to 41.00 MPa) [47-49]. PU-MCO2/L30 presented the highest Young modulus in comparison with recent published results concerning $100 \%$ bio-based polyols based polyurethanes [23, 50,51].

\section{Conclusions}

Polyurethanes based on renewable raw materials (technical Kraft lignin, castor oil and modified castor oil) were prepared. The results indicated that the starting materials change the polymer's properties. The oil modification process improved hydroxyl concentration and lead to polyurethanes with enhanced mechanical properties versus ones synthesized from unmodified castor oil. The introduction of TKL increased the glass transition temperature of the materials from $-0.76^{\circ} \mathrm{C}$ for PU-CO to $47.5^{\circ} \mathrm{C}$ for PU$\mathrm{CO} / \mathrm{L} 30$ and had a twofold effect on the mechanical properties. The reinforcement co-monomer and further increase in hydroxyl content led to a higher crosslinking density. The products show the feasibility of developing polyurethane-type materials with large property range, by using an industrial low cost, unmodified and largely available residue combined with no edible renewable source oil.

\section{Acknowledgements}

The authors thank FAPESP/CNPq and acknowledge UFABC (Federal University of ABC) for the doctoral fellowship of L.T. and A.N., the master fellowship of C.B. and G.S. and financial support.

\section{References}

[1] Bernardini J., Cinelli P., Anguillesi I., Coltelli M-B., Lazzeri A.: Flexible polyurethane foams green production employing lignin or oxypropylated lignin. European Polymer Journal, 64, 147-156 (2015). DOI: $10.1016 /$ j.eurpolymj.2014.11.039
[2] Huber G. W., Iborra S., Corma A.: Synthesis of transportation fuels from biomass: Chemistry, catalysts, and engineering. Chemical Reviews, 106, 4044-4098 (2006).

DOI: $10.1021 / \mathrm{cr} 068360 \mathrm{~d}$

[3] Zhang L., Zhang M., Hu L., Zhou Y.: Synthesis of rigid polyurethane foams with castor oil-based flame retardant polyols. Industrial Crops and Products, 52, 380388 (2014). DOI: $10.1016 /$ j.indcrop.2013.10.043

[4] Karak N., Rana S., Cho J. W.: Synthesis and characterization of castor-oil-modified hyperbranched polyurethanes. Journal of Applied Polymer Science, 112, 736743 (2009).

DOI: $10.1002 / a p p .29468$

[5] Zhang M., Pan H., Zhang L., Hu L., Zhou Y.: Study of the mechanical, thermal properties and flame retardancy of rigid polyurethane foams prepared from modified castor-oil-based polyols. Industrial Crops and Products, 59, 135-143 (2014). DOI: $10.1016 /$ j.indcrop. 2014.05 .016

[6] Gallezot P.: Conversion of biomass to selected chemical products. Chemical Society Reviews, 41, 1538-1558 (2012).

DOI: $10.1039 / \mathrm{C} 1 \mathrm{CS} 15147 \mathrm{~A}$

[7] Sharma C., Kumar S., Unni A. R., Aswal V. K., Rath S. K., Harikrishnan G.: Foam stability and polymer phase morphology of flexible polyurethane foams synthesized from castor oil. Journal of Applied Polymer Science, 131, 8420-8427 (2014).

DOI: $10.1002 / a p p .40668$

[8] Mutlu H., Meier M. A. R.: Castor oil as a renewable resource for the chemical industry. European Journal of Lipid Science and Technology, 112, 10-30 (2010). DOI: $10.1002 /$ ejlt.200900138

[9] Mosiewicki M. A., Dell'Arciprete G. A., Aranguren M. I., Marcovich N. E.: Polyurethane foams obtained from castor oil-based polyol and filled with wood flour. Journal of Composite Materials, 43, 3057-3072 (2009). DOI: $10.1177 / 0021998309345342$

[10] Lora J.: Industrial commercial lignins: Sources, properties and applications. in 'Monomers, polymers and composites from renewable resources' (eds: Belgacem M. N., Gandini A.) Elsevier, Amsterdam, 225-241 (2008).

DOI: 10.1016/B978-0-08-045316-3.00010-7

[11] Duval A., Lawoko M.: A review on lignin-based polymeric, micro- and nano-structured materials. Reactive and Functional Polymers, 85, 78-96 (2014). DOI: $10.1016 /$ j.reactfunctpolym.2014.09.017

[12] Kandula M., Schwenke T., Friebel S., Salthammer T.: Effect of ball milling on lignin polyesterification with E-caprolactone. Holzforschung, 69, 297-302 (2015). DOI: $10.1515 / \mathrm{hf}-2014-0053$

[13] Braun J. L., Holtman K. M., Kadla J. F.: Lignin-based carbon fibers: Oxidative thermostabilization of kraft lignin. Carbon, 43, 385-394 (2005).

DOI: $10.1016 /$ j.carbon.2004.09.027 
[14] Norberg I., Nordström Y., Drougge R., Gellerstedt G., Sjöholm E.: A new method for stabilizing softwood kraft lignin fibers for carbon fiber production. Journal of Applied Polymer Science, 128, 3824-3830 (2013). DOI: $10.1002 /$ app. 38588

[15] Gordobil O., Delucis R., Egüés I., Labidi J.: Kraft lignin as filler in PLA to improve ductility and thermal properties. Industrial Crops and Products, 72, 46-53 (2015). DOI: $10.1016 /$ j.indcrop.2015.01.055

[16] Schorr D., Diouf P. N., Stevanovic T.: Evaluation of industrial lignins for biocomposites production. Industrial Crops and Products, 52, 65-73 (2014).

DOI: $10.1016 /$ j.indcrop.2013.10.014

[17] Spiridon I., Leluk K., Resmerita A. M., Darie R. N.: Evaluation of PLA-lignin bioplastics properties before and after accelerated weathering. Composites Part B: Engineering, 69, 342-349 (2015).

DOI: $10.1016 /$ j.compositesb.2014.10.006

[18] Mohamed H. A., Badran B. M., Rabie A. M., Morsi S. M. M.: Synthesis and characterization of aqueous (polyurethane/aromatic polyamide sulfone) copolymer dispersions from castor oil. Progress in Organic Coatings, 77, 965-974 (2014).

DOI: $10.1016 /$ j.porgcoat.2014.01.026

[19] de Oliveira F. D., Ramires E. C., Frollini E., Belgacem M. N.: Lignopolyurethanic materials based on oxypropylated sodium lignosulfonate and castor oil blends. Industrial Crops and Products, 72, 1-10 (2015). DOI: $10.1016 / j$.indcrop.2015.01.023

[20] Cinelli P., Anguillesi I., Lazzeri A.: Green synthesis of flexible polyurethane foams from liquefied lignin. European Polymer Journal, 49, 1174-1184 (2013). DOI: $10.1016 /$ j.eurpolymj.2013.04.005

[21] Yeganeh H., Mehdizadeh M. R.: Synthesis and properties of isocyanate curable millable polyurethane elastomers based on castor oil as a renewable resource polyol. European Polymer Journal, 40, 1233-1238 (2004). DOI: $10.1016 /$ j.eurpolymj.2003.12.013

[22] Huo S-P., Nie M-C., Kong Z-W., Wu G-M., Chen J.: Crosslinking kinetics of the formation of lignin-aminated polyol-based polyurethane foam. Journal of Applied Polymer Science, 125, 152-157 (2012).

DOI: 10.1002/app.35401

[23] Zhang C., Wu H., Kessler M. R.: High bio-content polyurethane composites with urethane modified lignin as filler. Polymer, 69, 52-57 (2015).

DOI: $10.1016 /$ j.polymer.2015.05.046

[24] Das S., Pandey P., Mohanty S., Nayak S. K.: Influence of $\mathrm{NCO} / \mathrm{OH}$ and transesterified castor oil on the structure and properties of polyurethane: Synthesis and characterization. Materials Express, 5, 377-389 (2015). DOI: $10.1166 /$ mex.2015.1254

[25] Gurunathan T., Mohanty S., Nayak S. K.: Isocyanate terminated castor oil-based polyurethane prepolymer: Synthesis and characterization. Progress in Organic Coatings, 80, 39-48 (2015). DOI: $10.1016 /$ j.porgcoat.2014.11.017
[26] Wong C. S., Badri K. H.: Chemical analyses of palm kernel oil-based polyurethane prepolymer. Materials Science and Applications, 3, 78-86 (2012).

DOI: $10.4236 / \mathrm{msa} .2012 .32012$

[27] Luo X., Mohanty A., Misra M.: Lignin as a reactive reinforcing filler for water-blown rigid biofoam composites from soy oil-based polyurethane. Industrial Crops and Products, 47, 13-19 (2013).

DOI: $10.1016 /$ j.indcrop.2013.01.040

[28] García A., Erdocia X., González M. A., Labidi J.: Effect of ultrasound treatment on the physicochemical properties of alkaline lignin. Chemical Engineering and Processing: Process Intensification, 62, 150-158 (2012). DOI: $10.1016 /$ j.cep.2012.07.011

[29] Nada A-A. M. A., Yousef M. A., Shaffei K. A., Salah A. M.: Infrared spectroscopy of some treated lignins. Polymer Degradation and Stability, 62, 157-163 (1998). DOI: 10.1016/S0141-3910(97)00273-5

[30] Pietrzak K., Kirpluks M., Cabulis U., Ryszkowska J.: Effect of the addition of tall oil-based polyols on the thermal and mechanical properties of ureaurethane elastomers. Polymer Degradation and Stability, 108, 201211 (2014).

DOI: $10.1016 /$ j.polymdegradstab.2014.03.038

[31] Sormana J-L., Meredith J. C.: High-throughput discovery of structure-mechanical property relationships for segmented poly(urethane-urea)s. Macromolecules, 37, 2186-2195 (2004).

DOI: $10.1021 / \mathrm{ma} 035385 \mathrm{v}$

[32] Corcuera M. A., Rueda L., Fernandez D’Arlas B., Arbelaiz A., Marieta C., Mondragon I., Eceiza A.: Microstructure and properties of polyurethanes derived from castor oil. Polymer Degradation and Stability, 95, 2175-2184 (2010).

DOI: $10.1016 /$ j.polymdegradstab.2010.03.001

[33] Chattopadhyay D. K., Webster D. C.: Thermal stability and flame retardancy of polyurethanes. Progress in Polymer Science, 34, 1068-1133 (2009).

DOI: $10.1016 /$ j.progpolymsci.2009.06.002

[34] D'souza J., Camargo R., Yan N.: Polyurethane foams made from liquefied bark-based polyols. Journal of Applied Polymer Science, 131, 1-10 (2014).

DOI: 10.1002/app.40599

[35] Hablot E., Zheng D., Bouquey M., Avérous L.: Polyurethanes based on castor oil: Kinetics, chemical, mechanical and thermal properties. Macromolecular Materials and Engineering, 293, 922-929 (2008).

DOI: $10.1002 /$ mame.200800185

[36] Kang S. M., Lee S. J., Kim B. K.: Shape memory polyurethane foams. Express Polymer Letters, 6, 6369 (2012).

DOI: $10.3144 /$ expresspolymlett.2012.7

[37] Calvo-Correas T., Gabilondo N., Alonso-Varona A., Palomares T., Corcuera M. A., Eceiza A.: Shape-memory properties of crosslinked biobased polyurethanes. European Polymer Journal, 78, 253-263 (2016). DOI: $10.1016 /$ j.eurpolymj.2016.03.030 
[38] Nair M. N. R., Sukumar P., Jayashree V., Nair M. R. G.: Mechanical properties and fractography of block copolymers based on NR and MDI-based polyurethanes. Polymer Bulletin, 65, 83-96 (2010).

DOI: $10.1007 / \mathrm{s} 00289-010-0251-8$

[39] Ionescu M.: Chemistry and technology of polyols for polyurethane. Rapra, Shawbury (2007).

[40] Jang B. Z., Pater R. H., Soucek M. D., Hinkley J. A.: Plastic deformation mechanisms in polyimide resins and their semi-interpenetrating networks. Journal of Polymer Science Part B: Polymer Physics, 30, 643-654 (1992).

DOI: 10.1002/polb.1992.090300701

[41] Mullins M. J., Liu D., Sue H-J.: Mechanical properties of thermosets. in 'Thermosets: Structure, properties and applications' (ed.: Guo Q.) Woodhead, Oxford (2012). DOI: 10.1533/9780857097637.1.28

[42] Elder T.: Quantum chemical determination of Young's modulus of lignin. Calculations on a $\beta-\mathrm{O}-4^{\prime}$ model compound. Biomacromolecules, 8, 3619-3627 (2007). DOI: $10.1021 / \mathrm{bm} 700663 \mathrm{y}$

[43] Li Y., Ragauskas A. J.: Kraft lignin-based rigid polyurethane foam. Journal of Wood Chemistry and Technology, 32, 210-224 (2012). DOI: $10.1080 / 02773813.2011 .652795$

[44] Mahmood N., Yuan Z., Schmidt J., Xu C.: Preparation of bio-based rigid polyurethane foam using hydrolytically depolymerized Kraft lignin via direct replacement or oxypropylation. European Polymer Journal, 68, 1-9 (2015).

DOI: $10.1016 /$ j.eurpolymj.2015.04.030
[45] Banea M. D., da Silva L. F. M., Carbas R. J. C., Campilho R. D. S. G.: Mechanical and thermal characterization of a structural polyurethane adhesive modified with thermally expandable particles. International Journal of Adhesion and Adhesives, 54, 191-199 (2014). DOI: $10.1016 /$ j.ijadhadh.2014.06.008

[46] Clauss S., Gabriel J., Karbach A., Matner M., Niemz P.: Influence of the adhesive formulation on the mechanical properties and bonding performance of polyurethane prepolymers. Holzforschung, 65, 835-844 (2011).

DOI: 10.1515/HF.2011.095

[47] Prisacariu C.: Polyurethane elastomers: From morphology to mechanical aspects. Springer, Viena (2011).

DOI: 10.1007/978-3-7091-0514-6

[48] Wang H. H., Mou J., Ni Y. H., Fei G. Q., Si C. L., Zou J.: Phase behavior, interaction and properties of acetic acid lignin-containing polyurethane films coupled with aminopropyltriethoxy silane. Express Polymer Letters, 7, 443-455 (2013).

DOI: 10.3144/expresspolymlett.2013.41

[49] Kupka V., Vojtova L., Fohlerova Z., Jancar J.: Solvent free synthesis and structural evaluation of polyurethane films based on poly(ethylene glycol) and poly(caprolactone). Express Polymer Letters, 10, 479-492 (2016). DOI: 10.3144/expresspolymlett.2016.46

[50] Lee A., Deng Y.: Green polyurethane from lignin and soybean oil through non-isocyanate reactions. European Polymer Journal, 63, 67-73 (2014). DOI: $10.1016 /$ j.eurpolymj.2014.11.023

[51] Madhukar B. S., Bhadre Gowda D. G., Annadurai V., Somashekar R., Siddaramaiah: Phase behaviors of PU/SPI green composites using SAXS profiles. Advances in Polymer Technology, 35, 21526/1-21526/10 (2016).

DOI: $10.1002 / a d v .21526$ 